\title{
How Does Objective and Subjective Human Papillomavirus Knowledge Affect Information-Seeking Intentions and Source Preferences?
}

\author{
Danae Manika* \\ School of Business and Management, Queen Mary University of London, Mile End Road, \\ London, E14NS, UK; phone: +44 (0)20 7882 6541; fax: +44 (0)20 7882 3615; \\ e-mail: $\underline{\text { d.manika@qmul.ac.uk }}$
}

Patricia A. Stout, Stan Richards School of Advertising \& Public Relations, The University of Texas at Austin, 300 West Dean Keeton, A1200, BMC 4.338, Austin, TX 78712; phone: 512-471- 1101; fax: 512-471-7018; e-mail: pstout@mail.utexas.edu

Linda L. Golden, McCombs School of Business, Department of Marketing, B6700, The University of Texas at Austin, 2110 Speedway, Austin, TX 78705; phone: 512-663 8506; email: utlindagolden@gmail.com

Michael Mackert, Stan Richards School of Advertising \& Public Relations, The University of Texas at Austin, 300 West Dean Keeton, Austin, TX 78712; phone: 512-471-8558; fax: 512-471-7018; e-mail: mackert@mail.utexas.edu

Acknowledgements: Appreciation is extended to the Center for Risk Management and Insurance Research and to the Gus Wortham Chair in Risk Management for data collection funding.

\footnotetext{
* Corresponding Author
} 


\section{Authors Information Page}

Danae Manika (Ph.D., University of Texas at Austin)

Lecturer in Marketing

School of Business and Management

Queen Mary University of London

Mile End Road, London, E14NS, UK.

phone: $+44(0) 2078826541$

fax: +44 (0)20 78823615

e-mail: d.manika@qmul.ac.uk

Patricia A. Stout (Ph.D., University of Illinois at Urbana-Champaign)

Professor and Chair

Stan Richards School of Advertising \& Public Relations

The University of Texas at Austin

300 West Dean Keeton, A1200, BMC 4.338, Austin, TX 78712

phone: 512-471-1101

fax: 512-471-7018

e-mail:pstout@mail.utexas.edu

Linda L. Golden (Ph.D., University of Florida)

Shelby H. Carter, Jr. and Patricia Carter Regents Professorship in Global Business

McCombs School of Business, Department of Marketing, B6700

The University of Texas at Austin

2110 Speedway, Austin, TX 78705

phone: 512-663 8506

e-mail: utlindagolden@gmail.com

Michael Mackert (Ph.D., Michigan State University)

Associate Professor

Stan Richards School of Advertising \& Public Relations

The University of Texas at Austin

300 West Dean Keeton, Austin, TX 78712

phone: 512-471-8558

fax: 512-471-7018

e-mail: mackert@mail.utexas.edu 


\title{
How Does Objective and Subjective Human Papillomavirus Knowledge Affect Information-Seeking Intentions and Source Preferences?
}

\begin{abstract}
This study examines the effects of objective (factual information) and subjective knowledge (an individual's self-assessment of how much knowledge s/he has) on information-seeking intentions and source preferences. It explores the human papillomavirus (HPV) knowledge inequalities in groups of young adults aged 18-26 years with and without vaccinations and diagnosis, and different demographics/socio-economic and perceptions of health status. Higher subjective HPV knowledge leads to greater information-seeking intentions from family/friends and mass media but not from health professionals and the Internet. Objective HPV knowledge did not matter for information-seeking. The important role of demographics/socio-economic and perceived health status is also discussed.
\end{abstract}

Keywords: objective knowledge, subjective knowledge, information-seeking intentions and source preferences, HPV, demographics/socio-economic status, perceived health status 
In 1993 Moorman and Matulich anticipated that health care would change in the decade to follow with people taking more active roles in their own care. This prediction turned out to be an understatement for the whole of healthcare due to the propelling influences of new delivery techniques, pandemic threats, changes in insurance, the Internet's growth, as well as telecommunications and travel ease around the world to keep us connected.

People are now motivated toward self-care by public health issues faced around the world (e.g., cancer, obesity, H1N1 flu, HPV, Ebola, the newest quickly spreading MERS virus). Accompanied by new scientific breakthroughs in treatment and prevention, effective public health communication prevention programs are increasingly necessary. Health professionals and communicators often must convince people to change their habits and health behaviors, sometimes at a financial cost (Jayanti and Burns, 1998). "Preventative health care presents an interesting marketing challenge" (Jayanti and Burns, 1998, p. 6). It is not a new idea that simply increasing a person's "factual" knowledge accuracy (objective knowledge) about a health risk often is not enough to elicit behavioral change, as new knowledge may be misperceived or rejected (Fessenden-Raden, Fitchen, and Heath, 1987).

Health professionals continue to struggle with the issues around how to communicate effectively so as to motivate prevention behavior and maybe always will. This paper contributes to overcoming the motivational struggle by investigating the influence of different types knowledge and how they work to motivate prevention behaviors (or not). The importance of knowledge to information processing and decision-making is well documented (Alba and Hutchinson, 2000; Brucks, 1985; Johnson and Russo, 1984; Manika and Golden, 2011; Moore and Lehmann, 1980; Raju, Lonial, and Mangold, 1995). Knowledge guides "the acquisition and organization of relevant information and aids in the selection of an appropriate strategy for evaluating options of choice" (Coupey and Narayanan, 1996, p. 716), linking knowledge to behavior. Knowledge stored in an individual's memory (objective 
knowledge) differs from his/her assessment or perception of how much s/he knows which is subjective knowledge (Brucks, 1985). This distinction between objective and subjective types of knowledge is important because people may think they know more than they actually do, which can affect future knowledge acquisition and behavior (Alba and Hutchinson, 2000).

In recent years, researchers have called for further investigation of the concept of knowledge (e.g., Carlson, Vincent, Hardesty, and Bearden, 2009; Brucks, 1985); however, few researchers have examined the impact of objective and subjective knowledge on healthrelated behavior (e.g., Kim and Park, 2010; Manika and Golden, 2011; Moorman, Brinberg, and Kidwell, 2004) and particularly on health-related information-seeking intentions and source preferences. We respond to that call, as given the multitude of competing sources of information existing today and increased opportunities for worldwide physical contact, effective preventative healthcare communications are more important than ever (in spite of medical advances in prevention/cures — new challenges constantly present themselves).

\section{Research Objectives and the Specific Case of the Human Papillomavirus}

Human papillomavirus (HPV) is one of the most common sexually transmitted diseases in the United States (CDC, 2015). The HPV vaccine is the first cancer-related prevention vaccine available and is one of the most significant scientific breakthroughs of the 21st century (Fayed, 2008). No others have followed to date. Given the newness of the HPV vaccine and its frequent news coverage, health communication researchers have shown an increasing interest in the topic (e.g., Leader et al., 2011; Park, 2012; D'Souza, et al., 2013). HPV-related literature calls for further research on the effects of demographics and socioeconomic status on HPV knowledge (Polonijo and Carpiano, 2013). In response, this research examines demographics and socio-economic status and HPV knowledge and also acknowledges that self-perceptions of knowledge quantity (subjective knowledge) is not always accurate or consistent with the "currently factual" information stored in memory 
(objective knowledge). This conceptual distinction between objective and subjective knowledge can be traced to Socrates, who said "I know that I know nothing". This research also goes beyond demographics and socio-economic status to investigate the relationships between objective and subjective HPV knowledge and information-seeking intentions and source preferences - strategic variables of high relevance to health communications.

The newness of the HPV vaccine (first became available to the public in 2006), its frequent news coverage, and aggressive promotion through direct-to-consumer pharmaceutical advertisements make it an appropriate case for the investigation of how objective and subjective knowledge may affect health-related information-seeking and source preferences. Given that the HPV vaccine only protects individuals from certain HPV types, it is important for both vaccinated and unvaccinated individuals to stay updated with HPV information, another task for health communicators.

The Health Belief Model (HBM) is a popular and long-standing health behavior theory developed by Rosenstock (1974) and used to conceptually guide parts of this inquiry. The HBM is relevant to preventive health behaviors, such as behaviors related to HPV prevention information-seeking. The HBM recognizes knowledge as an antecedent of the likelihood of carrying out a recommended behavior e.g., information-seeking. Consistent with the HBM, our investigation includes the constructs of an individual's perceived susceptibility, severity, and self-efficacy as predictors of the likelihood of informationseeking across demographics/socio-economic groups.

This research focus on young adults aged 18-26 years because they have the highest rates of HPV infection (Bosch and De Sanjose, 2007). It is expected that whether people have been vaccinated against or diagnosed with HPV affects their knowledge and information receptivity. Knowledge resulting from experience has been considered subjective knowledge (Flynn and Goldsmith, 1999). With subjective knowledge, people learn specific aspects about 
a topic, which in turn may have different effects on decision making than objective knowledge (Raju et al., 1995). As conceptualized here, subjective knowledge relates to how much a person believes s/he knows and personal experience can impact that strongly. Therefore, differences between groups with and without vaccination and diagnosis are investigated, as well as SES (e.g., age, gender, income, education) and perceived health status differences that may also affect the processing and retention of a health communication message.

Thus, the goals of this research are twofold: (1) to examine the distinct impacts of objective and subjective HPV knowledge on HPV information-seeking intentions and source preferences and (2) to explore differences between young adults with and without HPV vaccination and diagnosis, demographics/socio-economic groups and perceived health status. Our theoretical guidance comes from the knowledge literature and the Health Belief Model.

\section{BACKGROUND AND HYPOTHESES}

\section{Objective and Subjective Knowledge}

In general, the knowledge construct refers to an individual's knowledge of a topic (Brucks, 1985; Moorman et al., 2004). According to Brucks (1985), a conceptual difference exists between objective and subjective knowledge. Subjective knowledge, which refers to self-perceptions of knowledge quantity, includes an individual's perceived level of confidence in his or her knowledge, while objective knowledge refers only to what the individual actually knows (accuracy of knowledge of "current facts"). Objective knowledge and subjective knowledge are unique constructs, with unique measures and influences (Flynn and Goldsmith, 1999; Park, Mothersbaugh, and Feik, 1994; Brucks, 1985; Moorman et al., 2004; Rudell, 1979), and tend to be positively correlated (Carlson et al., 2009; Moorman et al., 2004; Raju et al., 1995). 
Research has investigated objective and subjective knowledge relative to intangible situations (e.g., product nutrition, AIDS, H1N1 virus), providing support for their relevance to health information-seeking and behavior (Brucks, 1985; Golden and Stanaland, 2000; Manika and Golden, 2011; Moorman et al., 2004). Therefore, it is anticipated that objective and subjective HPV knowledge are positively and significantly associated with each other (Carlson et al., 2009).

H1: Objective and subjective HPV knowledge are positively and significantly associated with each other.

\section{Knowledge, Health Information Seeking, and Source Preferences}

Knowledge is a robust variable that has a significant impact on information seeking (Kahlor, 2010); however, prior research provides varying results for the relationship between knowledge and search behavior (negative relationship [Moore and Lehmann, 1980], positive relationship [Johnson and Russo, 1984]). Researchers have tried to reduce these inconsistencies by employing Brucks's (1985) definitions and operationalizations of objective and subjective knowledge (Golden and Stanaland, 2000; Manika and Golden, 2011; Moorman et al., 2004; Raju et al., 1995).

In their study on disease prevention, Golden and Stanaland (2000) find that individuals with greater objective AIDS knowledge were more likely to be receptive to external disease prevention information than individuals with lesser objective knowledge. They also find that subjective knowledge was inversely related to information receptivity, indicating that the more people thought they knew about AIDS prevention, the less receptive they were to related information.

Note that the effects of objective and subjective knowledge may be different for disease prevention information-seeking intentions and other behaviors. For example, a consumer behavior study examining the effects of nutrition knowledge on purchase behavior finds that individuals with greater subjective knowledge lack the motivation to engage in 
search behaviors because they think they know more than they actually do (Alba and Hutchinson, 2000); however, Moorman et al. (2004) find that individuals with lesser subjective knowledge lack the perceived ability to seek and/or interpret additional information. Therefore, only individuals with moderate levels of subjective knowledge are likely to seek information. However, Moorman et al. (2004) use a past search behavior measure, in contrast with other disease prevention studies, which use an intentions measure, which might explain these mixed results.

This research focuses on how objective and subjective knowledge affects intentions to seek HPV information from specific information sources: interpersonal (individuals, health professionals, family/friends), mass media, and the Internet. In line with Golden and Stanaland's (2000) results, it is expected that objective HPV knowledge will have a positive, significant effect on information-seeking intentions through interpersonal sources, mass media, and the Internet and that subjective HPV knowledge will have a negative, significant effect. Therefore, the following hypotheses are advanced on the basis of the aforementioned literature and prior research findings:

H2: Objective HPV knowledge has a positive and significant effect on HPV-related information-seeking intentions through (a) health professionals, (b) family/friends, (c) the Internet, and (d) mass media.

H3: Subjective HPV knowledge has a negative and significant effect on HPV-related information-seeking intentions through (a) health professionals, (b) family/friends, (c) the Internet, and (d) mass media.

\section{The Health Belief Model (HBM)}

The HBM predicts the likelihood of engaging in various disease (e.g., obesity, AIDS) prevention behaviors, among other health behaviors (i.e., mammography, breast selfexamination). In addition to objective knowledge, the HBM identifies perceived susceptibility, severity, and self-efficacy, among others, as predictors of the likelihood of health behavior change (Glanz et al., 2008). Perceived susceptibility and severity refer to an 
individual's health-related risk assessment of a certain condition/situation and the seriousness of the condition's potential consequences, respectively (Glanz et al., 2008). Perceived susceptibility can be a strong predictor of behavior when dealing with preventive actions (Janz and Becker, 1984). Perceived self-efficacy refers to the perceived ability of an individual to carry out the recommended health-related action (Bandura, 1994), and thus it can affect health behavior (Witte, Cameron, Lapinski, and Nzyuko, 1998). It is expected that individuals with greater perceived susceptibility, severity, and self-efficacy will be more likely to engage in HPV prevention behaviors (Glanz et al., 2008).

HPV knowledge, whether objective or subjective, may come from information provided to the public through health communication campaigns or public health messages and education programs. These messages often provide sources that people can go to for more information (e.g., doctor, websites) beyond the message itself (which may encourage a specific disease prevention behavior). The activity of seeking information can also be viewed "as one step in health behavior change, but more focused on the decision-making steps" (Freimuth, Stein, and Kean, 1989, p. 6), which in turn may impact disease prevention behavior (Glanz et al., 2008; Ratchford, 2008). Thus, individuals with greater perceptions of susceptibility and severity and self-efficacy are expected to be more likely to seek additional information from any source.

H4: Perceived susceptibility has a positive and significant effect on HPV-related information-seeking intentions through (a) health professionals, (b) family/friends, (c) the Internet, and (d) mass media.

H5: Perceived severity has a positive and significant effect on HPV-related information-seeking intentions through (a) health professionals, (b) family/friends, (c) the Internet, and (d) mass media.

H6: Perceived self-efficacy has a positive and significant effect on HPV-related information-seeking intentions through (a) health professionals, (b) family/friends, (c) the Internet, and (d) mass media. 
Most HPV studies have focused on non-vaccinated individuals, thus neglecting the need for further information-seeking after HPV vaccination. The vaccine protects against only two types of cancers (CDC, 2015), so even those who have had the HPV vaccine need to keep up to date with relevant HPV information and engage in further prevention behaviors (e.g., condoms, few sexual partners). Therefore, this study explores HPV prevention information-seeking intentions, for both vaccinated and non-vaccinated individuals. In addition, differences in objective and subjective HPV knowledge, and information-seeking intentions and source preferences between vaccinated and non-vaccinated individuals, SES, and health status are explored, although specific hypotheses are not advanced.

\section{METHODOLOGY}

A self-administered online Internet survey was developed, pre-tested and administered, via a USA online Internet consumer panel. Preliminary scale reliabilities (Cronbach's alphas) based on the pretest data $(n=106)$ showed that all measured constructs had alphas greater than .87 , and exploratory factor analyses (EFAs) indicated a one-factor solution per construct, indicating reliability and validity respectively. The sample frame for both the pretest and the main study was specified to include men and women aged 18-26 years. The sample was geographically and demographically dispersed. For the main study, the panel company sent out 10,800 e-mail invitations to prospective participants, 1,707 of whom filled out the survey. The resulting sample size was 1,476 participants, $25.8 \%$ of whom had been vaccinated against HPV and 5.9\% diagnosed with HPV. Table 1 provides additional demographic and health status statistics.

Insert Table 1 About Here

Survey measurements were based on prior established scales (see Table 2). Objective knowledge was measured using an HPV knowledge test consisting of 12 items developed 
from the current medical literature. The number of items with correct answers (compared to current "facts" known) were summed to create an objective knowledge composite score for each participant. This part of the questionnaire was developed from CDC information about HPV, and it was verified by a group of health professionals to ensure accuracy of the "current fact" answers. In addition, we measured whether or not participants were vaccinated against or diagnosed with HPV as categorical variables (Yes, No, Prefer not to disclose, Do not know). "Yes" answers were coded as 1 and "No" as 0 ; all others were coded as missing. We also measured participants' age, gender, education level, household income, and perceived health status.

Insert Table 2 About Here

\section{ANALYSES AND RESULTS}

All multi-item scales had Cronbach's alphas equal to or greater than .87 , well above the cutoff value of .70. EFAs were run (using Varimax rotation) for each multi-item scale. All Kaiser-Meyer-Olkin values for each scale were between .5 and 1, indicating the appropriateness of the analysis. Bartlett's test of sphericity showed that the results for each scale were significant $(p \leq .001)$ across all multi-item scales, and the changes in eigenvalues from the first to the second factor extracted for each scale were substantial, indicating a onefactor solution for each scale. Factor loadings were significant and close to each other for each multi-item scale. Thus, all multi-item measurement scales were both reliable and valid. In addition, none of the inter-correlations among the constructs were greater than .85 (Dijkstra, Buist, and Dassen, 1998), signifying discriminant validity. Table 2 also shows the factor loadings and reliabilities of the multi-item constructs, and Table 3 shows their intercorrelations, along with their means and standard deviations. Multi-collinearity diagnostics 
also indicated no signs of extreme multi-collinearity by the variance inflation factor $(<2.69)$ and tolerance (> .37) levels for each construct.

As it can be seen from Table 3, H1 was supported; objective and subjective HPV knowledge were positively and significantly associated with each other $(\mathrm{r}=.59, p \leq .01)$.

\section{Impact of HPV Knowledge on Information-Seeking Intentions}

Four regressions were conducted, with four dependent variables: information-seeking intentions through health professionals, family/friends, mass media, and the Internet. As shown in Table 4, across these regressions, objective knowledge had no significant impact on information seeking, thus $\mathrm{H} 2$ was not supported. Subjective knowledge had a negative and significant impact on information seeking from family/friends $(\mathrm{H} 3 \mathrm{~b}: \beta=.09, p \leq .01)$ and mass media (H3d: $\beta=-.11, p \leq .01)$. Hypothesis 3 was supported for these two sources.

Insert Table $3 \& 4$ About Here

Across all information sources, perceived susceptibility (H4) and severity (H5) were negatively and significantly related to information seeking. Even though these relationships were significant, $\mathrm{H} 4$ and $\mathrm{H} 5$ were not supported, as the effects were negative and not the anticipated positive associations. H6a, H6b, and H6d were supported with higher selfefficacy being associated with information seeking from health professionals, family and friends and mass media, respectively. It is interesting to note that seeking information via the Internet was not significantly related to self-efficacy, thus not supporting H6c. However, the independent variables explained $48 \%$ of the variance in information seeking from the Internet, which was greater than the variance explained in information seeking from health professionals, family/friends, and mass media (see Table 4). It appears that different sources evidence a relationship that varies with different types of knowledge and HBM individual characteristics (e.g., self-efficacy). 
Gender, age, education, income, perceived health status, whether or not participants were HPV vaccinated, and HPV diagnosed or not were independent variables in all four regressions in order to control for these effects (non-hypothesized exploratory purposes). Gender was significantly related to mass media information seeking $(\beta=.09, p \leq .01)$. Perceived health status was positively and significantly related to information seeking from all sources, except family/friends. Receiving HPV vaccination was negatively and positively related to seeking information from health professionals and family/friends, respectively $(\beta=.08, p \leq .05 ; \beta=.07, p \leq .05)$. These results are further explored in sub-sequent analysis.

\section{Young Adults With and Without HPV Vaccination}

HPV-vaccinated participants, as expected, had greater objective and subjective knowledge $\left(\mathrm{t}_{(\mathrm{df}=1053)}=-5.67, p \leq .01 ; \mathrm{t}_{(\mathrm{df}=1122)}=-7.16, p \leq .01\right.$, respectively $)$. Non-HPV-vaccinated participants were significantly more likely than vaccinated participants to seek information from health professionals $\left(\mathrm{t}_{(\mathrm{df}=1130)}=4.22, p \leq .01\right)$ and family/friends $\left(\mathrm{t}_{(\mathrm{df}=1125)}=3.60, p \leq .01\right)$. HPV-vaccinated participants had significantly lower perceptions of self-efficacy $\left(\mathrm{t}_{(\mathrm{df}=1128)}=5.37, p \leq .01\right)$ than non-HPV-vaccinated participants; however, the two groups did not differ in terms of perceptions of susceptibility and severity.

A chi-square difference test explored HPV-vaccinated and non-vaccinated men and women differences. Female participants were significantly more likely to be vaccinated against HPV than males $\left(\chi^{2}=50.25, p \leq .01\right)$. T-tests indicated significant differences in ages for HPV-vaccinated and non-vaccinated participants with younger participants more likely to be vaccinated than older participants. No significant differences emerged between HPVvaccinated and non-vaccinated groups for education, household income, and health status.

\section{Young Adults With and Without HPV Diagnosis}

As expected, participants diagnosed with HPV had greater objective and subjective knowledge $\left(\mathrm{t}_{(\mathrm{df}=1247)}=-4.69, p \leq .01 ; \mathrm{t}_{(\mathrm{df}=1329)}=-7.15, p \leq .01\right.$, respectively $)$. Non-HPV-diagnosed 
participants were significantly more likely than HPV-diagnosed participants to seek information from health professionals $\left(\mathrm{t}_{(\mathrm{df}=1336)}=4.02, p \leq .01\right)$, family/friends $\left(\mathrm{t}_{(\mathrm{df}=1330)}=3.27\right.$, $p \leq .01)$, mass media $\left(\mathrm{t}_{(\mathrm{df}=1324)}=2.73, p \leq .01\right)$, and the Internet $\left(\mathrm{t}_{(\mathrm{df}=1329)}=2.78, p \leq .01\right)$.

HPV-diagnosed participants had significantly higher perceptions of susceptibility and severity than non-HPV-diagnosed participants $\left(\mathrm{t}_{(\mathrm{df}=1345)}=-10.56, p \leq .01 ; \mathrm{t}_{(\mathrm{df}=1346)}=-8.41, p \leq .01\right.$, respectively), though the two groups did not differ in perceived self-efficacy. A chi-square difference test showed no significant differences in gender for HPV-diagnosed and nondiagnosed participants. A t-test indicated that older participants were more likely to have been diagnosed with HPV than younger participants $\left(\mathrm{t}_{(\mathrm{df}=1451)}=-3.51, p \leq .01\right)$. Health status also varied significantly $\left(\mathrm{t}_{(\mathrm{df}=1347)}=4.14, p \leq .01\right)$, with most $(68$ of 87$)$ participants diagnosed with HPV describing their health as "good," "very good," and "excellent." No significant differences emerged in education and household income for HPV-diagnosed and nondiagnosed participants.

\section{Demographics/Socio-economic Groups And Perceived Health Status}

Women were significantly more likely to have greater objective knowledge $\left(\mathrm{t}_{(\mathrm{df}=1350)}=-10.59, p \leq .01\right)$, and subjective knowledge $\left(\mathrm{t}_{(\mathrm{df}=1446)}=-8.47, p \leq .01\right)$ than men, though they had lower information-seeking intentions through health professionals $\left(t_{(d f=1452)}=3.84\right.$, $p \leq .01)$ and family/friends $\left(\mathrm{t}_{(\mathrm{df}=1446)}=2.08, p \leq .05\right)$. No significant differences emerged for information-seeking intentions via Internet and mass media. In addition, women were also significantly more likely to have greater perceived severity $\left(\mathrm{t}_{(\mathrm{df}=1465)}=-1.95, p \leq .05\right)$ and lesser perceived self-efficacy $\left(\mathrm{t}_{(\mathrm{df}=1451)}=6.12, p \leq .01\right)$ than men. No significant differences emerged for perceived susceptibility between genders.

A series of one-way analyses of variance (ANOVAs) explored differences among age, education, household income, and perceived health status. Differences based on participants' ages for objective and subjective knowledge could not be compared because Levene's test of 
sphericity was significant, preventing interpretation of results. Comparison between age differences in terms of source preferences of information-seeking intentions indicated no significant differences among participants.

Educational differences emerged for objective and subjective knowledge $\left(\mathrm{F}_{(8}\right.$, $1339)=4.05, p \leq .01 ; \mathrm{F}_{(8,1431)}=2.33, p \leq .05$, respectively) but not for information-seeking intentions. As expected, participants with higher education qualifications had greater objective and subjective knowledge than those with lower education qualifications.

There were significant household income differences for objective knowledge $\left(\mathrm{F}_{(7,1332)}=2.19, p \leq .05\right)$, with higher objective knowledge scores for higher income persons. No differences existed for subjective knowledge and information-seeking intentions through all sources, except health professionals (not testable as Levene's test was significant).

Only statistically significant objective knowledge test scores $\left(\mathrm{F}_{(4,1343)}=4.49, p \leq .01\right)$, could be compared across groups for different perceptions of health status. People in the "fair," "good," and "very good" categories had higher objective knowledge than those in the "poor" and "excellent" groups. Perceived severity also differed by perceived health status

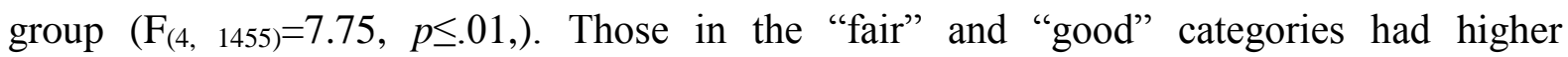
perceptions of severity than those in the "poor," "very good," and "excellent" health groups.

\section{Summary of Results By Hypothesis}

A summary of the hypothesis support is shown in Table 5, which is discussed in the next section, along with marketing recommendations for the design of health communication endeavors and future research directions.

Insert Table 5 About Here

\section{CONCLUSIONS AND IMPLICATIONS}

This research contributes to the health behavior literature by demonstrating that objective and subjective health knowledge are both central to motivating prevention behavior, 
and that they have differential effects on health information seeking and source preferences. Stakes are high when a life threatening disease is spreading, sparking a great need to understand health knowledge behavioral effects and inform the design and implementation of disease prevention marketing. The findings have important health marketing implications.

What individuals think they know (i.e., subjective health knowledge) is more important for motivating information seeking behaviors, than is factually correct knowledge held (i.e., objective health knowledge); particularly for information seeking through family, friends and mass media. Health marketing communication messages should raise awareness among individuals regarding their need for more knowledge regarding a disease to stimulate disease prevention information seeking through mass media, and family/friends. An individual's perception of his/her health knowledge is a strong determinant of information seeking intentions. Health communicators might incorporate surprising facts or interrogatives in their marketing (e.g., What percentage of people are diagnosed with HPV every year?) to increase interest and message elaboration (Manika and Gregory-Smith, 2014). This would help motivate additional information seeking, either through discussions with family/friends or media/marketing receptivity.

It is a new finding that health marketing communication messages should not only focus on educating individuals through objective knowledge: Health marketers should also consider the target audience's subjective knowledge and aim to illustrate the need for and motivate additional knowledge acquisition without creating a defensive information barrier/block. Future research is needed to investigate creative and effective ways of making the target market aware of their need to up-to-date objective knowledge without creating a defensive block to acquiring new information (e.g., using interrogative headlines).

Interestingly, neither objective nor subjective knowledge appears to motivate information-seeking intentions through health professionals or the Internet. Seeking 
information from health professionals requires greater commitment and effort (i.e., often the need to make an appointment or travel) than does seeking information from family/friends and mass media, both of which are more easily accessible. Further research is needed to explore factors that might be important for motivating information seeking through health professionals and the Internet.

Our findings suggest that health marketing messages should both use the fear reaction to stimulate information seeking while also reducing the audience's perceptions of susceptibility and severity so as to avoid generating fear control processes (see Witte 1992) that can reduce information seeking. Future research is needed to test creative messaging strategies to accomplish this fine line of promotion. It is possible that this goal might be reached by creatively using the third person in messaging while stimulating word of mouth.

This finding contradicts the Health Belief Model (HBM) predictions, however, the HBM focuses on motivating actual prevention behaviors, not information-seeking behaviors. Thus, a very important conclusion of this research is that actual prevention and informationseeking behaviors need different health marketing communication strategies and messages to be effective in motivating behavior. In addition, the results suggest that the target audience may need to be segmented for high versus low susceptibility and severity disease perceptions. Individuals on the lower end of susceptibility/severity may be more likely to seek additional information after exposure to a message that illustrates the importance of keeping health risk information updated.

Conversely, individuals on the higher end of severity may need to be exposed to messages motivating danger control process, rather than fear control processes, as per Witte (1992), to increase information seeking intentions. Again, increasing the importance of knowing the facts is relevant, as is impacting perceptions of self-efficacy and responseefficacy information seeking (Witte, 1992). And, our self-efficacy results support this 
marketing implication. As people are more confident of their message interpretation, the more likely they are to seek information, except for the Internet as a source. Possibly, other factors intervene in the Internet situation (e.g., perceived ability to use the Internet, access to a computer, etc.).

It is very important that health marketers target their message at a level that all may understand if broadly delivered (Mackert, 2012; Ball, Manika and Stout, 2011) and that communicators thoroughly understand the Internet competence and site usage habits of the audience (e.g., see www.XXX). This implication is increasingly poignant for all communication given that electronic messaging is going to occur in today's world whether the health communication professional intends it or not. And, telecommunications messaging knows no geo-political boundaries - information can be spread in a heartbeat and that spread is relatively uncontrollable. Marketers must keep the world in mind even when targeting locally: Target locally, think globally.

It is evident that information-seeking intentions via health professionals, family/friends, the Internet and mass media, are very different sources strategically and are impacted by knowledge dimensions in different ways. Relevant to the importance of knowing the target market well and audience segmentation, this research supports and extends Polonijo and Carpiano's (2013) findings and also contributes to the HPV knowledge disparities literature. Higher education begets greater objective and subjective knowledge. Persons with more education may have more confidence in their knowledge, even if (objective) knowledge is not accurate.

Health status self-perceptions are also important for health marketers to understand. At the extremes, "poor" and "excellent" health, information is not sought-information seeking is enhanced for self-assessed "fair," "good," and "very good" health status selfevaluations (from family/friends and mass media). Amplifying this is the relationship of 
health status and knowledge dimensions. Strategically important is that people at the extremes (highest and lowest health status perceptions) are less likely to seek information and had lower objective knowledge--knowing the facts less (than mid-level health status people). Possibly, people who perceive themselves to be in "excellent" health think they are more invincible and people in poor health just do not want to know.

With the need/motivation to know absent among the highest and lowest health quality self-perception groups, they are going to be the hardest targets to reach. They are not receptive and the "excellent" health people may not know what they do not know-another barrier to health prevention information receptivity. Thus, health marketers may need to consider target segmentation based on the relationship between health status and knowledge to tailor messages more effectively. Given that people in poor health may be in critical need of prevention behaviors and the others in "excellent health" may be very dangerous to society with their incorrect knowledge perceptions, this is a critically important area for further investigation. Significant also is that self-perceptions are not always accurate such that those perceiving themselves to be in "excellent health" may pose a danger to society well beyond their lack of accurate objective knowledge! Effective health marketing is important to all, especially in a disease crisis, such as a pandemic, and we cannot wait for the crisis to better understand disease prevention marketing effectiveness.

HPV-vaccinated or HPV-diagnosed participants, as expected, have significantly greater objective and subjective knowledge of HPV than non-vaccinated and non-diagnosed participants. This is consistent with prior research that posits that certain types of knowledge come from experience (Raju et al., 1995). However, the causal relationships posited in prior research may be reversed: It may be the impact of dimensions of knowledge that motivate people (here to vaccinate). For HIV and maybe other diseases as well, health marketers should consider specifically targeting to HPV-vaccinated and HPV-diagnosed individuals, 
They may have greater objective and subjective knowledge perceptions, which via discussions through family and friends, may increase non-HPV vaccinated and diagnosed individuals' objective knowledge and decrease initially subjective knowledge perceptions respectively (which can increase additional information seeking).

Demographics and socio-economic status are very important to the effects of knowledge dimensions and to information seeking and acquisition. Our objective knowledge dimension (how well one knows "current facts") is a measure of knowledge acquisition: If someone has acquired the knowledge readily and publicly available. Thus, this research reaches to dimensions of knowledge, as well as prior acquisition and intention to seek information from specific sources. Since demographics and socio-economic status are relatively easy variables for segmentation, this finding is very strategically useful.

The findings regarding the impact of objective and subjective knowledge on HPVrelated information-seeking intentions through interpersonal and mass media sources, strongly imply that a one-size-fits-all health communication message strategy might not be effective in motivating all types (i.e. via all sources) of HPV information-seeking behaviors for all groups (as per Manika and Gregory-Smith, 2014). And, demographics and socioeconomic status correlates make it easier to strategically develop, differentially targeted and create more effective prevention messaging.

In conclusion, even though results cannot be generalized beyond the methodology and characteristics of this study, distinctions in the impacts of different dimensions of knowledge are important and should be considered in health marketing communications. Informational needs may vary significantly. This research is an important contribution to better understanding the role of knowledge sources, specific information sources, and HBM constructs, such as self-efficacy, on health marketing effectiveness. It provides practical and actionable implications and a fertile area for further investigation. 


\section{REFERENCES}

Alba, J.G., \& Hutchinson, J.G. (2000) Knowledge calibration: what consumers know and what they think they know. Journal of Consumer Research, 27(2), 123-156.

Ball, J.G., Manika, D. \& Stout, P. (2011) Consumers Young and Old: Segmenting the Target Markets for Direct-to-Consumer Prescription Drug Advertising, Health Marketing Quarterly, 28:4, 337-353.

Bandura, A. (1994) Social cognitive theory and control over HIV. In R. DiClemente \& J. Peterson (Eds.), Preventing AIDS: theories and methods of behavioral interventions (pp. 2359). New York: Plenum Press.

Bosch, F.X., \& De Sanjose, S. (2007) The epidemiology of human papillomavirus infection and cervical cancer. Disease Markers, 23(4), 213-227.

Brucks, M. (1985) The effects of product class knowledge on information search behavior. Journal of Consumer Research, 12, 1-16.

Burton, S., Garretson, J.A., \& Velliquette, A.M. (1999) Implications of accurate usage of nutrition facts panel and information for food product evaluations and purchase intentions. Journal of the Academy of Marketing Science, 27(4), 470-481.

Carlson, J.P., Vincent, L.G., Hardesty, D.M., \& Bearden, G.O. (2009) Objective and subjective knowledge relationships: a quantitative analysis of consumer research findings. Journal of Consumer Research, 35(5), 864-876.

CDC. (2015) STDs: HPV. Available from http://www.cdc.gov/std/hpv/.

Coupey, E., \& Narayanan, S. (1996) Effects of knowledge types on choice quality and perceptions of choice performance. Psychology \& Marketing, 13(7), 715-738.

D'Souza, C., Mort, G.S., Zyngier, S., Robinson, P.\& Schlotterlein, M. (2013) Preventative Innovation: An Australian Case Study on HPV Vaccination. Health Marketing Quarterly, $30: 3,206-220$. 
Dijkstra, A., Buist, G., \& Dassen, T. (1998) A criterion-related validity study of the nursing care dependency. International Journal of Nursing Studies, 35, 163-170.

Fayed, L. (2008) How to prevent and reduce your risk of HPV. About.com. Retrieved from http://cervicalcancer.about.com/od/riskfactorsandprevention/a/hpv_prevention.htm.

Fessenden-Raden, J., Fitchen, M., \& Heath, S. (1987) Providing risk information in communities: factors influencing what is hears and accepted. Science, Technology, and Human Values, 12(3/4), 94-101.

Flynn, L. R., \& Goldsmith, R. E. (1999) A short reliable measure of subjective knowledge. Journal of Business Research, 46(1), 57-66.

Freimuth, V. S., Stein, J. A., \& Kean, T. J. (1989) Searching for health information: The Cancer Information Service model. Philadelphia, PA: University of Pennsylvania Press.

Glanz, K., Rimer, B.K., \& Viswanath, K. (2008) Health Behavior and Health Education: Theory, Research, and Practice. San Francisco, John Wiley \& Sons.

Golden, L.L., \& Stanaland, A.J.S. (2000) Consumer Receptivity to Social Marketing Information: The Role of Self-Rated Knowledge and Knowledge Accuracy. ANZMAC 2000. Janz, N.K., \& Becker, M.H. (1984) The Health Belief Model: a decade later. Health Education Quarterly, 11(1), 1-47.

Jayanti, R.K., \& Burns, A.C. (1998). The antecedents of preventative health care behavior: an empirical study. Journal of the Academy of Marketing Science, 26, 6-15.

Johnson, E.J., \& Russo, J.E. (1984) Product familiarity and learning new information, Journal of Consumer Research, 11, 542-550.

Kahlor, L. (2010) PRISM: A planned risk information-seeking model. Health Communication, 25(4), 345-356. 
Kim, K., \& Park, J.S. (2010) Message framing and the effectiveness of DTC advertising: The moderating role of subjective product knowledge. Journal of Medical Marketing, 10(2), 165-176.

Leader, A.E., Cashman, R., Voytek, C.D., Baker, J.L., Brawner, B.M. \& Frak, I. (2011) An Exploratory Study of Adolescent Female Reactions to Direct-to-Consumer Advertising: The Case of the Human Papillomavirus (HPV) Vaccine, Health Marketing Quarterly, 28:4, 372385.

Mackert, M. (2012) Account Planning: Applying an Advertising Discipline to Health Communication and Social Marketing. Health Marketing Quarterly, 29:3, 270-282.

Manika, D., \& Golden, L.L. (2011) Self-efficacy, Threat, Knowledge, and Information Receptivity: Exploring Pandemic Prevention Behaviors to Enhance Societal Welfare. Academy of Health Care Management Journal, 7(1): 31-44.

Manika, D., \& Gregory-Smith, D. (2014) Health marketing communications: An integrated conceptual framework of key determinants of health behaviour across the stages-of-change, Journal of Marketing Communications, DOI:10.1080/13527266.2014.946436

Moore, G.L., \& Lehmann, D.R. (1980) Individual differences in search behavior for a nondurable. Journal of Consumer Research, 7(3), 296-307.

Moorman, C. D. K., Brinberg, D., \& Kidwell, B. (2004) Subjective knowledge, search location, and consumer choice. Journal of Consumer Research, 31(December), 673-680.

Moorman, C., \& Matulich, E. (1993) A model of consumers' preventive health behavior: The role of health motivation and health ability. Journal of Consumer Research, 20, 208-228.

Park, C.W., Mothersbaugh, D.L., \& Feik, L. (1994) Consumer knowledge assessment. Journal of Consumer Research, 8, 71-82. 
Park, S-Y. (2012) The Effects of Message Framing and Risk Perceptions for HPV Vaccine Campaigns: Focus on the Role of Regulatory Fit. Health Marketing Quarterly, 29:4, 283302.

Polonijo, A.N., \& Carpiano, R.M. (2013) Social inequalities in adolescent human papillomavirus (HPV) vaccination: a test of fundamental cause theory. Social Science \& Medicine, 82, 115-125.

Raju, P.S., Lonial, S.C., \& Mangold, G.G. (1995) Differential effects of subjective knowledge, objective knowledge, and usage experience on decision-making: an exploratory investigation. Journal of Consumer Psychology, 4, 153-180.

Ratchford, B.T. (2008) Consumer search behavior and its effect on markets. Foundations and Trends in Marketing, 3(1), 1-74.

Rosenstock, I. (1974) Historical origins of the health belief model. Health Education Monographs, 2(4), 328-335.

Witte, K. (1992) Putting the fear back into fear appeals: the extended parallel process model. Communication Monographs, 59, 329-349.

\section{TABLES}

Table 1. Sample Demographics And Characteristics

\begin{tabular}{|c|c|c|c|}
\hline & & Frequency & Percentage \\
\hline $\begin{array}{l}\text { Gender } \\
(\mathrm{N}=1476)\end{array}$ & $\begin{array}{l}\text { Male } \\
\text { Female }\end{array}$ & $\begin{array}{l}714 \\
762\end{array}$ & $\begin{array}{l}48.4 \% \\
51.6 \%\end{array}$ \\
\hline $\begin{array}{l}\text { Age } \\
(\mathrm{N}=1468)\end{array}$ & $\begin{array}{l}18-20 \\
21-23 \\
24-26\end{array}$ & $\begin{array}{l}588 \\
408 \\
472\end{array}$ & $\begin{array}{l}40.0 \% \\
27.8 \% \\
32.2 \%\end{array}$ \\
\hline $\begin{array}{l}\text { Education } \\
(\mathrm{N}=1468)\end{array}$ & $\begin{array}{l}\text { Some high school or less } \\
\text { High school graduate or equivalent } \\
\text { Vocational/technical school (two year program) } \\
\text { Some college but no degree } \\
\text { College graduate (four year program) } \\
\text { Some graduate school } \\
\text { Graduate degree } \\
\text { Professional degree (M.D., J.D., etc.) } \\
\text { Other ("finished", "white", "good") }\end{array}$ & $\begin{array}{l}99 \\
348 \\
55 \\
585 \\
244 \\
45 \\
69 \\
20 \\
3\end{array}$ & $\begin{array}{r}6.7 \% \\
23.6 \% \\
3.7 \% \\
39.9 \% \\
16.6 \% \\
3.2 \% \\
4.7 \% \\
1.4 \% \\
.2 \%\end{array}$ \\
\hline $\begin{array}{l}\text { Household Income } \\
(\mathrm{N}=1461)\end{array}$ & $\begin{array}{l}\text { Less than } \$ 15,000 \\
\$ 15,000 \text { to } \$ 24,999 \\
\$ 25,000 \text { to } \$ 34,999 \\
\$ 35,000 \text { to } 49,999 \\
\$ 50,000 \text { to } 74,999 \\
75,000 \text { to } 99,999 \\
\$ 100,000 \text { to } \$ 149,999\end{array}$ & $\begin{array}{l}266 \\
200 \\
216 \\
256 \\
259 \\
129 \\
88\end{array}$ & $\begin{array}{r}18.2 \% \\
13.7 \% \\
14.8 \% \\
17.5 \% \\
17.7 \% \\
8.8 \% \\
6.0 \%\end{array}$ \\
\hline
\end{tabular}




\begin{tabular}{|c|c|c|c|}
\hline & $\$ 150,000$ or more & 47 & $3.2 \%$ \\
\hline $\begin{array}{l}\text { Health Status } \\
(\mathrm{N}=1468)\end{array}$ & $\begin{array}{l}\text { Poor } \\
\text { Fair } \\
\text { Good } \\
\text { Very Good } \\
\text { Excellent }\end{array}$ & $\begin{array}{l}16 \\
151 \\
544 \\
524 \\
233\end{array}$ & $\begin{array}{r}1.1 \% \\
10.3 \% \\
37.1 \% \\
35.7 \% \\
15.9 \%\end{array}$ \\
\hline $\begin{array}{l}\text { HPV Vaccinated } \\
(\mathrm{N}=1470)\end{array}$ & $\begin{array}{l}\text { Yes } \\
\text { No } \\
\text { Prefer not to disclose } \\
\text { Do not know }\end{array}$ & $\begin{array}{l}381 \\
767 \\
49 \\
273\end{array}$ & $\begin{array}{l}25.9 \% \\
52.2 \% \\
3.3 \% \\
18.6 \%\end{array}$ \\
\hline $\begin{array}{l}\text { HPV Diagnosed } \\
(\mathrm{N}=1466)\end{array}$ & $\begin{array}{l}\text { Yes } \\
\text { No } \\
\text { Prefer not to disclose } \\
\text { Do not know }\end{array}$ & $\begin{array}{l}87 \\
1269 \\
35 \\
75\end{array}$ & $\begin{array}{l}5.9 \% \\
86.6 \% \\
2.4 \% \\
5.1 \%\end{array}$ \\
\hline
\end{tabular}

Table 2. Questionnaire Items and Measurement Checks

\begin{tabular}{|c|c|c|}
\hline Constructs & $\begin{array}{l}\text { Std. EFA } \\
\text { Loadings }\end{array}$ & $\begin{array}{l}\text { Cronbach's } \\
\text { Alpha }\end{array}$ \\
\hline Objective HPV Knowledge & & $\mathrm{n} / \mathrm{a}$ \\
\hline What is "HPV"? a & n/a & \\
\hline HPV transmission can happen with any skin to skin contact with the genital area of an infected person. ${ }^{b}$ & $\mathrm{n} / \mathrm{a}$ & \\
\hline Intercourse is NOT necessary. ${ }^{\mathrm{b}}$ & $\mathrm{n} / \mathrm{a}$ & \\
\hline HPV affects ${ }^{b}$ & $\mathrm{n} / \mathrm{a}$ & \\
\hline How many types of HPV are there, which can infect the genital area? ${ }^{\mathrm{b}}$ & $\mathrm{n} / \mathrm{a}$ & \\
\hline Certain types of HPV can lead to cervical cancer in women. ${ }^{b}$ & $\mathrm{n} / \mathrm{a}$ & \\
\hline Certain types of HPV can lead to genital warts. ${ }^{\text {b }}$ & $\mathrm{n} / \mathrm{a}$ & \\
\hline Approximately 20 million Americans are currently infected with HPV. ${ }^{\mathrm{b}}$ & $\mathrm{n} / \mathrm{a}$ & \\
\hline Which of the following is NOT a way to reduce the risk of contracting HPV? ${ }^{a}$ & n/a & \\
\hline The HPV vaccine(s) is/are NOT AT ALL effective when given after a person's first sexual contact. $^{b}$ & $\mathrm{n} / \mathrm{a}$ & \\
\hline An individual may have HPV even if he/she has no symptoms. ${ }^{\text {b }}$ & $\mathrm{n} / \mathrm{a}$ & \\
\hline At least $50 \%$ of sexually active people will have genital HPV at some time in their lives. ${ }^{b}$ & $\mathrm{n} / \mathrm{a}$ & \\
\hline The HPV vaccine(s) do(es) TREAT genital warts. ${ }^{\mathrm{b}}$ & $\mathrm{n} / \mathrm{a}$ & \\
\hline Subjective HPV Knowledge (adapted from Burton, Garretson, \& Velliquette, 1999; Moorman et al., 2004) & & .95 \\
\hline In general, how much do you think you know about HPV. ${ }^{c}$ & $.87 * *$ & \\
\hline In general, how much do you think you know about how to protect yourself from of having HPV. ${ }^{\mathrm{c}}$ & $.88^{* * *}$ & \\
\hline In general, how much do you think you know about the potential health consequences of having HPV. ${ }^{\mathrm{c}}$ & $.88^{* *}$ & \\
\hline Compared to most people, I am quite knowledgeable about HPV. ${ }^{\mathrm{d}}$ & $.91 * *$ & \\
\hline Compared to most people, I am quite knowledgeable about how to protect myself from having HPV. ${ }^{d}$ & $.91 * *$ & \\
\hline Compared to most people, I am quite knowledgeable about the potential health consequences of having HPV. ${ }^{\mathrm{d}}$ & $.91 * *$ & \\
\hline Perceived Susceptibility to HPV (adapted from Manika \& Golden, 2011) & & $\mathrm{n} / \mathrm{a}$ \\
\hline I believe I am personally at risk of getting infected with $\mathrm{HPV}^{\mathrm{d}}$ & $\mathrm{n} / \mathrm{a}$ & \\
\hline Perceived Severity of HPV (adapted from Manika \& Golden, 2011) & & $\mathrm{n} / \mathrm{a}$ \\
\hline How severe a threat is HPV to you personally? ${ }^{\mathrm{e}}$ & n/a & \\
\hline Perceived Self-efficacy related to HPV (adapted from Manika \& Golden, 2011) & & .96 \\
\hline How confident do you feel about your ability to make HPV prevention choices? ${ }^{f}$ & $.96^{* * *}$ & \\
\hline How confident do you feel about your ability to use your knowledge of HPV in making prevention choices? ${ }^{f}$ & $.97 * *$ & \\
\hline How confident do you feel about your ability to use your knowledge of HPV in making every day activity choices? ${ }^{f}$ & $.96^{* * *}$ & \\
\hline $\begin{array}{l}\text { HPV Information-seeking Intentions via Health Professionals (adapted from Kahlor, 2010; Manika \& Golden, } \\
\text { 2011) }\end{array}$ & & .95 \\
\hline In the future, how likely are you to talk to a health professional about HPV. ${ }^{g}$ & $.95 * *$ & \\
\hline In the future, how likely are you to talk to a health professional about how to protect yourself from having HPV. ${ }^{\mathrm{g}}$ & $.96^{* * *}$ & \\
\hline $\begin{array}{l}\text { In the future, how likely are you to talk to a health professional about the potential health consequences of having } \\
\text { HPV. }\end{array}$ & $.96^{* * *}$ & \\
\hline $\begin{array}{l}\text { HPV Information-seeking Intentions via Friends and Family (adapted from Kahlor, 2010; Manika \& Golden, } \\
\text { 2011) }\end{array}$ & & .97 \\
\hline In the future, how likely are you to talk to your friends and family about HPV. ${ }^{\mathrm{g}}$ & $.96 * *$ & \\
\hline $\begin{array}{l}\text { In the future, how likely are you to talk to your friends and family about how to protect yourself from having } \\
\text { HPV. }\end{array}$ & $.97^{* * *}$ & \\
\hline $\begin{array}{l}\text { In the future, how likely are you to talk to your friends and family about the potential health consequences of } \\
\text { having HPV.g }\end{array}$ & $.98^{* * *}$ & \\
\hline HPV Information-seeking Intentions via the Internet (adapted from Kahlor, 2010; Manika \& Golden, 2011) & & .97 \\
\hline In the future, how likely are you to search the Internet for HPV-related information. ${ }^{\mathrm{g}}$ & $.97 * *$ & \\
\hline $\begin{array}{l}\text { In the future, how likely are you to search the Internet for information on how to protect yourself from having } \\
\text { HPV. }{ }^{g}\end{array}$ & $.96^{\text {*** }}$ & \\
\hline $\begin{array}{l}\text { In the future, how likely are you to search the Internet for information about the potential health consequences of } \\
\text { having HPV. }\end{array}$ & $.97^{* * *}$ & \\
\hline HPV Information-seeking Intentions via Mass Media (adapted from Kahlor, 2010; Manika \& Golden, 2011) & & .98 \\
\hline
\end{tabular}




\begin{tabular}{|c|c|c|c|c|c|c|c|c|c|c|c|}
\hline \multicolumn{8}{|c|}{$\begin{array}{l}\text { In the future, how likely are you to search for information on mass media (e.g., TV, radio, newspapers) about } \\
\text { HPV. }{ }^{\text {g }}\end{array}$} & \multicolumn{2}{|c|}{$.98 * *$} & & \\
\hline \multicolumn{8}{|c|}{$\begin{array}{l}\text { In the future, how likely are you to search for information on mass media (e.g., TV, radio, newspapers) about how } \\
\text { to protect yourself from having HPV.g }\end{array}$} & \multicolumn{2}{|c|}{$.98 * *$} & & \\
\hline \multicolumn{8}{|c|}{$\begin{array}{l}\text { In the future, how likely are you to search for information on mass media (e.g., TV, radio, newspapers) about the } \\
\text { potential health consequences of having HPV.g }\end{array}$} & \multicolumn{2}{|c|}{$.98^{* *}$} & & \\
\hline \multicolumn{12}{|c|}{ 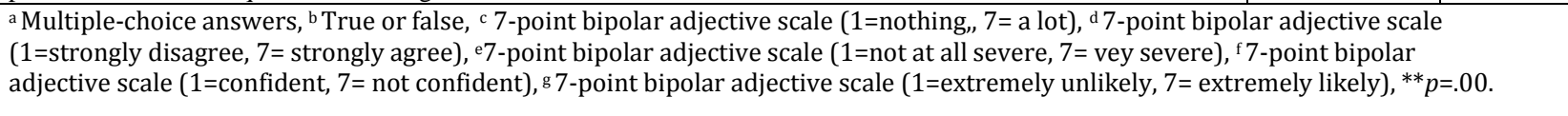 } \\
\hline \multicolumn{12}{|c|}{ Table 3. Descriptive Statistics And Correlations } \\
\hline Constructs & $\mathbf{N}$ & M (SD) & \multicolumn{9}{|c|}{ Correlations } \\
\hline Objective HPV Knowledge & 1352 & $5.95(3.50)$ & 1 & & & & & & & & \\
\hline Subjective HPV Knowledge & 1448 & $3.62(1.77)$ & $.59^{* *}$ & 1 & & & & & & & \\
\hline Perceived Susceptibility & 1464 & $2.62(1.57)$ & .02 & $.11^{* *}$ & 1 & & & & & & \\
\hline Perceived Severity & 1467 & $2.71(1.67)$ & $.07^{*}$ & $.21^{* *}$ & $.62^{* *}$ & 1 & & & & & \\
\hline Perceived Self-efficacy & 1453 & $3.76(1.99)$ & $-.38^{* *}$ & $-.46^{* *}$ & $.13^{* * *}$ & .05 & 1 & & & & \\
\hline $\begin{array}{l}\text { Information-seeking Intentions through } \\
\text { Health Professionals }\end{array}$ & 1454 & $4.07(1.93)$ & $-.12^{* *}$ & $-.16^{* *}$ & $-.20^{* *}$ & $-.23^{* *}$ & $.13^{* *}$ & 1 & & & \\
\hline $\begin{array}{l}\text { Information-seeking Intentions through } \\
\text { Family/Friends }\end{array}$ & 1448 & $4.35(1.96)$ & $-.14^{* *}$ & $-.20^{* * *}$ & $-.17^{* *}$ & $-.21^{* * *}$ & $.16^{* * *}$ & $.71^{* * *}$ & 1 & & \\
\hline $\begin{array}{l}\text { Information -seeking Intentions through } \\
\text { the Internet }\end{array}$ & 1449 & $3.99(2.01)$ & -.02 & -.05 & $-.17^{* *}$ & $-.21^{* * *}$ & .03 & $.70^{* * *}$ & $.65^{* *}$ & 1 & \\
\hline $\begin{array}{l}\text { Information-seeking Intentions through } \\
\text { Mass Media }\end{array}$ & 1444 & $4.80(1.92)$ & -.03 & $-.13^{* *}$ & $-.19^{* *}$ & $-.21^{* *}$ & $.09^{* *}$ & $.58^{* * *}$ & $.67^{* *}$ & $.65^{* *}$ & 1 \\
\hline
\end{tabular}

$* * p \leq .01 ; * p \leq .05$

Table 4. Regression Results: Intentions To Seek HPV Information And Source Preferences

\begin{tabular}{|c|c|c|c|c|c|c|c|c|c|c|c|c|}
\hline \multirow{2}{*}{$\begin{array}{l}\text { Dependent Variables } \\
\text { Independent Variables }\end{array}$} & \multicolumn{3}{|c|}{$\begin{array}{c}\text { Information-seeking } \\
\text { Intentions through Health } \\
\text { Professionals }(\mathrm{N}=1476)\end{array}$} & \multicolumn{3}{|c|}{$\begin{array}{l}\text { Information-seeking } \\
\text { Intentions through } \\
\text { Family/Friends }(\mathrm{N}=1476)\end{array}$} & \multicolumn{3}{|c|}{$\begin{array}{l}\text { Information-seeking } \\
\text { Intentions through the } \\
\text { Internet }(\mathrm{N}=1476)\end{array}$} & \multicolumn{3}{|c|}{$\begin{array}{c}\text { Information-seeking } \\
\text { Intentions through Mass } \\
\text { Media }(\mathrm{N}=1476)\end{array}$} \\
\hline & Beta & $\begin{array}{c}\text { St. } \\
\text { error }\end{array}$ & $\mathrm{t}$ & Beta & $\begin{array}{c}\text { St. } \\
\text { error }\end{array}$ & $\mathrm{t}$ & Beta & $\begin{array}{c}\text { St. } \\
\text { error }\end{array}$ & $\mathrm{t}$ & Beta & $\begin{array}{l}\text { St. } \\
\text { error }\end{array}$ & $\mathrm{t}$ \\
\hline Objective knowledge & -.01 & .02 & -.33 & -.03 & .02 & -.89 & .00 & .02 & .00 & .06 & .02 & 1.50 \\
\hline Subjective Knowledge & -.03 & .05 & -.75 & $-.09 *$ & .05 & -2.13 & .01 & .05 & .30 & $-.11 * *$ & .05 & -2.61 \\
\hline Perceived Susceptibility & $-.18 * *$ & .05 & -4.57 & $-.19 * *$ & .05 & -4.73 & $-.11 * *$ & .05 & -2.85 & $-.15 * *$ & .05 & -3.81 \\
\hline Perceived Severity & $-.12 * *$ & .04 & -3.01 & $-.07 *$ & .04 & -1.95 & $-.13 * *$ & .05 & -3.39 & $-.10 *$ & .04 & -2.48 \\
\hline Perceived Self-efficacy & $.10^{* *}$ & .03 & 2.88 & $.12 * *$ & .04 & 3.47 & .07 & .04 & 1.90 & $.07 *$ & .04 & 2.01 \\
\hline Gender & -.05 & .13 & -1.75 & .02 & .13 & .58 & .01 & .14 & .26 & $.09 * *$ & .13 & 2.70 \\
\hline Age & .06 & .02 & 1.68 & .04 & .02 & 1.06 & .00 & .03 & -.02 & .05 & .02 & 1.48 \\
\hline Education & -.03 & .04 & -.83 & .01 & .04 & .13 & -.02 & .04 & -.60 & .00 & .04 & -.09 \\
\hline Income & .04 & .03 & 1.25 & .05 & .03 & 1.51 & .02 & .03 & .67 & .05 & .03 & 1.54 \\
\hline Perceived Health Status & $.08 * *$ & .07 & 2.68 & .03 & .07 & .95 & $.09 * *$ & .07 & 2.81 & $.07 *$ & .07 & 2.15 \\
\hline HPV Vaccinated & $-.08 *$ & .13 & -2.50 & $-.07 *$ & .14 & -2.12 & -.03 & .14 & -.88 & -.02 & .14 & -.63 \\
\hline \multirow[t]{2}{*}{ HPV Diagnosed } & -.01 & .24 & -.20 & .01 & .24 & .27 & -.01 & .26 & -.26 & .01 & .24 & .43 \\
\hline & \multicolumn{3}{|c|}{$\begin{array}{l}\mathrm{R}^{2}=.11, \mathrm{p} \leq .01 ; \\
\mathrm{F}(12,957)=11.01, \mathrm{p} \leq .01\end{array}$} & \multicolumn{3}{|c|}{$\begin{array}{l}\mathrm{R}^{2}=.10, \mathrm{p} \leq .01 ; \\
\mathrm{F}(12,954)=10.02, \mathrm{p} \leq .01\end{array}$} & \multicolumn{3}{|c|}{$\begin{array}{l}\mathrm{R}^{2}=.48, \mathrm{p} \leq .01 ; \\
\mathrm{F}(11,169)=16.06, \mathrm{p} \leq .01\end{array}$} & \multicolumn{3}{|c|}{$\begin{array}{l}\mathrm{R}^{2}=.08, \mathrm{p} \leq .01 ; \\
\mathrm{F}(12,948)=7.62, \mathrm{p} \leq .01\end{array}$} \\
\hline
\end{tabular}

Table 5. Summary Of Results By Hypothesis

\begin{tabular}{|c|c|c|c|c|}
\hline \multicolumn{5}{|c|}{ SUMMARY OF RESULTS BY HYPOTHESIS } \\
\hline H1: Objective Knowledge WITH Subjective Knowledge & & $\mathbf{S}$ & & \\
\hline & Health Professionals & Family/Friends & The Internet & Mass Media \\
\hline H2: Objective Knowledge $\rightarrow$ Information-seeking Intentions & NS & NS & NS & NS \\
\hline H3: Subjective Knowledge $\rightarrow$ Information-seeking Intentions & NS & $\mathbf{S}$ & NS & $\mathbf{S}$ \\
\hline H4: Perceived Susceptibility $\rightarrow$ Information-seeking Intentions & NS* & NS* & NS* & NS* \\
\hline H5: Perceived Severity $\rightarrow$ Information-seeking Intentions & NS* & NS* & NS* & NS* \\
\hline H6: Perceived Self-efficacy $\rightarrow$ Information-seeking Intentions & $\mathbf{S}$ & $\mathbf{S}$ & NS & $\mathbf{S}$ \\
\hline
\end{tabular}

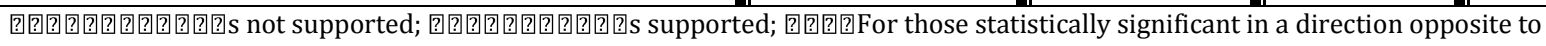
the one hypothesized. 